\title{
The Oxygen Paradox
}

\section{Monica Butnariu*}

Chemistry and Vegetal Biochemistry, Banat's University of Agricultural Sciences and Veterinary Medicine, Timisoara, Romania

"By denying scientific principles, one may maintain any paradox." Galileo Galilei

One of the life's paradoxes is the fact that the molecule supporting aerobic life-oxygen-is not just essential for the energetic metabolism and for respiration, but almost equally involved in the ethiopatogenesis of numerous diseases and degenerative states due to oxygen-based reactive species called free radicals (FR). Nature has selected and included, in an evolutionary manner, in the composition of living bodies, reactions generating FR with multiple roles: functional, intercellular communicational or destructive, cytolitic, etc. At molecular level the main target of the free radical is the sulphurhydril free or protein groups, while at cellular level the main target are cellular membranes. FR occurs in the body, as the result of endogenous metabolic activity or of the local assimilation of some chemical pollutants at cellular level or at the level of several tissues, simultaneously or gradually. Due to their high reactivity, FR has been found responsible for many noxious effects on the living body. Oxidative stress is defined as an exaggerated production of oxygenated FR, accompanied by a dislocation of antioxidation agents. We cannot live without oxygen, since it is essential in the functioning of energy-producing cells. A body transforms and eliminates oxygen $\left(\mathrm{CO}_{2}\right)$ properly almost entirely $(98 \%)$ [1].

Unfortunately, the rest is at the origin of some "hyper-reactive" species called FR (is oxidated derivatives of the electron deficit, unstable oxygen molecule, that cause dysfunctions of all body cells). The volume of oxygen contained by a single inspiration produces a billion FR.

Reactive oxygen species (ROS) are at the origin of chain reactions, such a radical, unstable as a result of the electron deficit, captures the missing electron from a "foreign" molecule that becomes, in its turn, an unstable radical, and the process goes on and on [2].

Such reactions occur quasi-instantaneously, at speeds of the order of billions/second, until the deficit electron is formed by a neuter, stable molecule, but whose physiological function is altered. It results in lesions of the nucleic acids involved in cell division or in protein synthesis that become incapable of transporting the oxygen necessary to the metabolism [3]. The activity of FR was described as a sort of "inner radiation" attacking and damaging cells/tissues, resulting in different symptoms usually attributed to ageing [4]. The damaging effects of normally producing ROS in the body are under control by specialised removal enzymes. Both diseases and adaptations to the environment are linked to the alteration of the body chemical metabolism characterised by the transition from heterolithic (2 electrons are attracted/released) to the increase of homolithic processes (1 electron is transited). Homolithic reactions produce radicals that can react, damaging cell compartments, tissues, and organisms. These reactions that generate ROS reach equilibrium through the inner increase of oxidative processes or by the presence of antioxidant compounds [5]. The main actions of ROS in a biological system are: oxidation of unsaturated fatty acids in the cell membrane, oxidation of aminoacids in proteins, depolymerisation of hialuric acid, oxidation of DNA oxidative products, modulation of the nucleotide cyclase activity, modulation of prostaglandin activity and synthesis, etc [6-8].
The current concepts of ROS signalling can be grouped into two action mechanisms:

- Alterations of intracellular redox state: Compared to the extra-cell environment, cytoplasm is normally maintained in reducing conditions (accompanied by the buffer redox capacity of intra-cell thiol such as GSH and TRX-thioredoxin). These thiol systems oppose intra-cell oxidative stress reducing $\mathrm{H}_{2} \mathrm{O}_{2}$, lipid superoxides and peroxides (catalysed by peroxidases).

- Protein oxidative changes: ROS can alter the structure and function of proteins, changing the rest of amino acids, inducing protein dimerisation and interacting with other metal complexes (Fe-S). Oxidative changes of amino acids in the protein functional domain can involve several pathways [9]. The target cell components of free radical action include lipids (low-density lipoproteins), macromolecules with complex structure, proteins and DNA.

In order to minimise the negative effects of ROS, organisms are endowed with very efficient antioxidant defence system [10]. In the presence of oxidative stress, i.e. of a positive oxidative balance the most vulnerable system of a body is the central nervous system. Health state analysis has thus shifted from cell level to molecular level (molecular biology-ROS) and to atomic level (atomic physics-electrons) [11-13]. This is the biochemical and biophysical context in which the action of anti-oxidative compounds, taking into account that oxidative stress, is responsible for about $80-90 \%$ of chronic-degenerative diseases associated to ageing.

The ageing is not a chronological process caused by the passage of time, but rather a biological process determined by the speed that ROS are assimilated by the body, destroying cells, attacking tissues, and affecting vital functions [14-17].

ROS produced by one's own body play a role in the cell defence system, destroying bacteria and viruses, decomposing chemical pollutants, and neutralising toxins [18].

Living organisms and, particularly, the encephalus, are very sensitive to the damage produced by FR [19]. Most probably, this is due to the following factors: electron-rich neuronal biomolecules (histidine, tryptophan, etc.) recognise the oxygen radical, an electrophilous ROS (it alters histaminergic and serotoninergic systems); neuronal

*Corresponding author: Monica Butnariu, Chemistry and Vegetal Biochemistry Banat's University of Agricultural Sciences and Veterinary Medicine 300645, Calea Aradului 119, Timis, Romania, Tel: +40-0-256-277-441; Fax: +40-0-256-200-296; E-mail: monica_butnariu@usab tm.ro, monica_butnariu@usab-tm.ro

Received January 08, 2012; Accepted January 11, 2012; Published January 14 2012

Citation: Butnariu M (2012) The Oxygen Paradox. J Pharmacogenom Pharmacoproteomics 3:e104. doi:10.4172/2153-0645.1000e104

Copyright: (c) 2012 Butnariu M. This is an open-access article distributed unde the terms of the Creative Commons Attribution License, which permits unrestricted use, distribution, and reproduction in any medium, provided the original author and source are credited. 
membranes are rich in polyunsaturated fatty acids (privileged molecular substratum of ROS); neuronal mitochondria are represented in large numbers (mitochondria are the cell core of FR); neurons are easily subjected to dedifferentiation as a result of the attack by ROS on the DNA (they lose their own genetic specialisation or differentiation and turn into neuter cells, with no specific function); neuronal oxygen is certainly present since the brain, unlike other organs and tissues, has an overall aerobic energetic metabolism [20-24]. At the brain level, there are small amounts of enzymatic and non-enzymatic antioxidants. Vitamin $\mathrm{C}$ is an exception, as it has, at brain level, a concentration 50 times higher than in any other part of the organism [25].

This is the key-substance for the protection of the central nervous system against FR. Neurons are "perennial cells" and the cumulated lesions produced by ROS on the different cell structures could, in time, degrade quantitatively and qualitatively, the neurotransmission functions and result in behavioural changes [26]. The postulate of the ageing theory is based on the reactions of FR involved in the changes caused by ageing. The changes are associated with the environment, with diseases, and with the intrinsic ageing process. This theory is based on the chemical nature of the reactions of ROS and on their omnipresence. The most reactive of all ROS is hydroxyl, which reacts with deoxiribose and the bases of the DNA. As a result of the postulate of the ageing theory, we can draw two conclusions on the relationship between the deterioration of the DNA and maximum life span. The increase agents/processes of the rate of deterioration of the DNA or the decrease of DNA recovery can speed up the ageing process. Thus, decreasing life span and apparent deterioration speed, we can decrease proportionally the speed of the specific metabolism (the energetic nutritional supplement). ROS are considered factors that cause cell dedifferentiation since they react with chromatin, they change the bases of the DNA, and they cause ruptures of the chain [27-29]; they induce chromosomal aberrations and a long life in the species with a low rate of accumulation of chromosomal aberrations; long life species have a low rate of accumulation of age pigments, lipofuscine, because ageing rate is proportional with metabolic rate for many different species [3032]. The factor determining the increase of the intensity of free radical formation is oxygen activation. Due to the presence of this element not only in the atmosphere but also in almost all the substances in the body, the interaction of FR with oxygen is inevitable [33]. They attack the existing pro-oxidants (substances/ions) for which the ROS have an affinity. ROS occur in certain reactions of oxidoreduction resulting in structural alterations, in most cases with the alteration of the biological function (it becomes more hydrosoluble or it intervenes in another chain of metabolic reactions) [34]. The human body has natural antioxidants; they make up a complex of enzymes, vitamins, metals, and aminoacids functioning in association at two levels: it identifies ROS and guides them towards antioxidant molecules that neutralise them and re-develop them again. Antioxidants donate or receive a supplementary electron to neutralise ROS and to put an end to the oxidation cascade of oxidation [35-37]. ROS forms at mitochondrial level, during the respiratory chain, as well as a result of enzymatic reactions. The speed of formation of ROS depends on the speed of use of the oxygen, and it is directly proportional with the number of mitochondria in the cell.

The importance of FR can only be understood if we know well their role.

Evolutively, nature has selected and included in the human body, reactions generating ROS with multiple roles: functional, intracellular communication, or destructive, cytolitic. If, at molecular level, the main target of the ROS is the free or protein groups $\mathrm{SH}$, at cellular level, the major goal is cell membranes. ROS can be formed in the body as a result of endogenous metabolic activity or of the assimilation of chemical pollutants-locally, at cell level, or in several tissues, simultaneously or gradually. Because of their high reactivity, ROS has been incriminated in many noxious body actions. As a conclusion, ROS and oxidative stress play an important role in the induction of dysfunctions at cell level and of different diseases at body level.

The balance between the antioxidant action of ROS and the level of antioxidants in a body is essential for life and it characterizes the capacity of resistance and adaptation of a living body.

"A perfection of means, and confusion of aims, seems to be our main problem." Albert Einstein

\section{References}

1. Matzinger $P$ (2007) Friendly and dangerous signals: is the tissue in control? Nat Immunol 8: 11-13.

2. Floyd RA (2009) Serendipitous findings while researching oxygen free radicals Free Radic Biol Med 46: 1004-1013.

3. Rizzo AM, Berselli P, Zava S, Montorfano G, Negroni M, et al. (2010) Endogenous antioxidants and radical scavengers. Adv Exp Med Biol 698: 5267.

4. Williams HE, Claybourn M, Green AR (2007) Investigating the free radical trapping ability of NXY-059, S-PBN and PBN. Free Radic Res 41: 1047-1052.

5. Gutierrez J, Ballinger SW, Darley-Usmar VM, Lander A (2006) Free radicals mitochondria, and oxidized lipids: the emerging role in signal transduction in vascular cells. Circ Res 99: 924-932.

6. Hathwar SC, Bijinu B, Rai AK, Narayan B (2011) Simultaneous recovery of lipids and proteins by enzymatic hydrolysis of fish industry waste using different commercial proteases. Appl Biochem Biotechnol 164: 115-124.

7. Gustafsson $\AA \mathrm{B}$, Gottlieb RA (2008) Heart mitochondria: gates of life and death Cardiovasc Res 77: 334-343

8. Cynshi O, Tamura K, Niki E (2010) Design, synthesis, and action of antiatherogenic antioxidants. Methods Mol Biol 610: 91-107.

9. Ozcan ME, Gulec M, Ozerol E, Polat R, Akyol O (2004) Antioxidant enzyme activities and oxidative stress in affective disorders. Int Clin Psychopharmaco 19: 89-95

10. Jankun J (2011) Protein-based nanotechnology: Antibody conjugated with photosensitizer in targeted anticancer photoimmunotherapy. Int J Oncol 39: 949-953.

11. Chander V, Chopra K (2005) Molsidomine, a nitric oxide donor and L-arginine protects against rhabdomyolysis-induced myoglobinuric acute renal failure. Biochim Biophys Acta 1723: 208-214

12. Valko M, Rhodes CJ, Moncol J, Izakovic M, Mazur M (2006) Free radicals metals and antioxidants in oxidative stress-induced cancer. Chem Biol Interact 160: $1-40$.

13. Pickrell AM, Fukui $H$, Moraes CT (2009) The role of cytochrome c oxidase deficiency in ROS and amyloid plaque formation. J Bioenerg Biomembr 41 453-456.

14. Sari I, Cetin A, Kaynar L, Saraymen R, Hacioglu SK, et al. (2008) Disturbance of pro-oxidative/antioxidative balance in allogeneic peripheral blood stem cell transplantation. Ann Clin Lab Sci 38: 120-125.

15. Surapaneni KM, Venkataramana G (2007) Status of lipid peroxidation, glutathione, ascorbic acid, vitamin $\mathrm{E}$ and antioxidant enzymes in patients with osteoarthritis. Indian J Med Sci 61: 9-14.

16. Takabe W, Li R, Ai L, Yu F, Berliner JA, et al. (2010) Oxidized Low-Density Lipoprotein-Activated C-Jun $\mathrm{NH}_{2}$-Terminal Kinase Regulates Manganese Superoxide Dismutase Ubiquitination. Implication for Mitochondrial Redox Status and Apoptosis. Arterioscler Thromb Vasc Biol 30: 436-441. 
17. Horvath G, Brubel R, Kovacs K, Reglodi D, Opper B, et al. (2011) Effects of PACAP on Oxidative Stress-Induced Cell Death in Rat Kidney and Human Hepatocyte Cells. J Mol Neurosci 43: 67-75.

18. Kaynar H, Meral M, Turhan H, Keles M, Celik G, et al. (2005) Glutathione peroxidase, glutathione-S-transferase, catalase, xanthine oxidase, Cu$\mathrm{Zn}$ superoxide dismutase activities, total glutathione, nitric oxide, and malondialdehyde levels in erythrocytes of patients with small cell and non-small cell lung cancer. Cancer Lett 227: 133-139.

19. Waris G, Ahsan H (2006) Reactive oxygen species: role in the development of cancer and various chronic conditions. J Carcinog 5: 14.

20. Orient A, Donko A, Szabo A, Leto TL, Geiszt M (2007) Novel sources of reactive oxygen species in the human body. Nephrol Dial Transplant 22: 1281-1288.

21. Budisavljevic MN, Hodge L, Barber K, Fulmer JR, Durazo-Arvizu RA, et al. (2003) Oxidative stress in the pathogenesis of experimental mesangial proliferative glomerulonephritis. Am J Physiol Renal Physiol 285: 1138-1148.

22. Haussinger D, Schliess F (2008) Pathogenetic mechanisms of hepatic encephalopathy. Gut 57: 1156-1165.

23. Montoliu C, Cauli O, Montoliu C, Rodrigo R, Llansola M, et al. (2009) Mechanisms of cognitive alterations in hyperammonemia and hepatic encephalopathy: Therapeutical implications. Neurochem Int 55: 106-112.

24. Pirker A, Kramer L, Voller B, Loader B, Auff E, et al. (2011) Type of Edema in Posterior Reversible Encephalopathy Syndrome Depends on Serum Albumin Levels: An MR Imaging Study in 28 Patients. AJNR Am J Neuroradiol 32: $527-$ 531.

25. Ajith TA, Usha S, Nivitha V (2007) Ascorbic acid and alpha-tocopherol protect anticancer drug cisplatin induced nephrotoxicity in mice: a comparative study. Clin Chim Acta 375: 82-86.

26. Lemberg A, Fernandez MA (2009) Hepatic encephalopathy, ammonia, glutamate, glutamine and oxidative stress. Ann Hepatol 8: 95-102.

27. O'Hare F, Watson R, O'Neill A, Donoghue V, O'Donnell C, et al. (2011)
Significantly Elevated Systemic Neutrophil Reactive Oxygen Intermediates are Associated with Severe Neonatal Encephalopathy. Pediatr Res 70: 684-684.

28. Wang D, Chen Y, Chabrashvili T, Aslam S, Borrego Conde LJ, et al. (2003) Role of oxidative stress in endothelial dysfunction and enhanced responses to angiotensin II of afferent arterioles from rabbits infused with angiotensin II. J Am Soc Nephrol 14: 2783-2789.

29. Shibata S, Nagase M, Yoshida S, Kawachi H, Fujita T (2007) Podocyte as the target for aldosterone: roles of oxidative stress and Sgk1. Hypertension 49: 355-364.

30. Sachse A, Wolf G (2007) Angiotensin II-induced reactive oxygen species and the kidney. J Am Soc Nephrol 18: 2439-2446.

31. Lambeth JD (2007) Nox enzymes, ROS, and chronic disease: an example of antagonistic pleiotropy. Free Radic Biol Med 43: 332-347.

32. Bhatti F, Mankhey RW, Asico L, Quinn MT, Welch WJ, et al. (2005) Mechanisms of antioxidant and pro-oxidant effects of alphalipoic acid in the diabetic and nondiabetic kidney. Kidney Int 67: 1371-1380.

33. Bakris GL (2007) Pharmacological augmentation of endothelium-derived nitric oxide synthesis. J Manag Car’e Pharm. 13: 9-12.

34. Fialkow L, Wang Y, Downey GP (2007) Reactive oxygen and nitrogen species as signaling molecules regulating neutrophil function. Free Radic Biol Med 42: 153-164.

35. Angermuller S, Islinger M, Volkl A (2009) Peroxisomes and reactive oxygen species, a lasting challenge. Histochem Cell Biol 131: 459-463.

36. Bonekamp NA, Volkl A, Fahimi HD, Schrader M (2009) Reactive oxygen species and peroxisomes: struggling for balance. Biofactors 35: 346-355.

37. Seo KW, Kim KB, Kim YJ, Choi JY, Lee KT, et al. (2004) Comparison of oxidative stress and changes of xenobiotic metabolizing enzymes induced by phthalates in rats. Food Chem Toxicol 42: 107-114. 